\title{
Hemisection : An alternative to extraction : A Case Report
}

\begin{abstract}
Hemisection is sectioning of multi-rooted teeth followed by removal of compromised root along with its associated crown portion and leaving the healthy root (with crown) intact. This treatment option can be considered when caries, resorption, perforation, or periodontal damage is restricted to one root while the other root is relatively healthy. The most critical factor determining the long term success in such cases is the appropriate case selection. This case report describes a case of hemisection of a mandibular molar followed by adequate restoration in a young patient.
\end{abstract}

Keywords: Hemisection; Furcation defect; Mandibular Molar; Endodontic surgery

\section{Introduction:}

Advanced dental therapeutic measures have provided opportunity to retain teeth that were once considered non restorable. Such therapeutic measures involve multidisciplinary approach. Hemisection is one such treatment modality involving principles of restorative dentistry, endodontics, periodontics, oral surgery and prosthodontics. [1]

It is a procedure carried out in a multirooted tooth wherein one-half of the crown and the associated unrestorable root is removed at the level of the furcation, while leaving the healthy portion of the crown and its associated root in function thus maintaining its integrity within the socket. The most critical factor determining the long term success in such cases is the appropriate case selection which involves a combined periodontal, endodontic and prosthodontic assessment. [2]

The guiding principle is the preservation of remaining tooth structure and restoration of the function. This case report describes a case in which hemisection was chosen as a treatment plan to retain the distal root of mandibular left first molar and extraction of untreatable mesial half of the tooth.[3]

\begin{tabular}{|l|l|}
\hline \multicolumn{2}{|c|}{ Access this article online } \\
\hline \multirow{2}{*}{$\begin{array}{l}\text { Website: } \\
\text { www.ujds.in }\end{array}$} & Quick Response Code \\
\hline $\begin{array}{l}\text { DOI: } \\
\text { https://doi.org/10.21276/ujds.2020.6.3.18 }\end{array}$ & \\
\hline
\end{tabular}

\section{Case Report:}

A 28 year old male patient reported with a chief complaint of broken tooth in lower left back teeth region. Patient gave the history of endodontic treatment with the same tooth 3 years back.

On intraoral examination lower left mandibular molar (tooth no. 36) was root canal treated with dislodged post endodontic filling. The mesial half of the tooth was grossly decayed with caries involving the pulpal floor at furcation area.

Radiographic examination of the tooth revealed radiolucency at pulpal floor, grossly decayed mesial half, incompletely obturated mesial and distal canals and periapical radiolucency (Figure-1). The ideal treatment was extraction of tooth no. 36 followed by replacement but patient was very keen on saving

\footnotetext{
${ }^{1}$ KHURANA, D., ${ }^{2}$ THANVI, C., ${ }^{3}$ RAISINGANI, D., ${ }^{4}$ ASHWINI, P. B.

${ }^{1-4}$ Department of Conservative Dentistry and Endodontics

${ }^{2,3}$ Mahatma Gandhi Dental College and General Hospital, Sitapura, RIICO Industrial Area, Jaipur.
}

Address for Corresponding : Dr. Deeksha Khurana Mahatma Gandhi Dental College and Hospital, Jaipur. Email : khurana.deeksha297@gmail.com

Received : 5 Nov. 2020, Published : 31 Dec. 2020

How to cite this article: Khurana, D., Thanvi, C., Raisingani, D., \& Ashwini, P. B. (2021). Hemisection: An alternative to extraction : A case report. UNIVERSITY JOURNAL OF DENTAL SCIENCES, 6(3). : 128 - 131 
the tooth. So the treatment plan was modified and it was decided to do re-root canal therapy of the distal root followed by hemisectioning of the mesial half of the tooth. The patient was informed about the treatment plan, informed consent was obtained.

Re-root canal procedure was started in the distal root of tooth no. [36]. Under rubber dam isolation, all the filling material and carious structure on the pulpal floor was removed using a round bur. Gutta percha was removed from the distal canal using retreatment files (Dentsply), working length was determined using radiographic methods and confirmed with the apex locataor ( $\mathrm{J}$ morita). Biomechanical shaping and cleaning was done with rotary files (ProTaper gold, Dentsply Maillefer) up to file size F1. Irrigation protocol consisted of thorough passive mechanical irrigation with $5.25 \%$ sodium hypochlorite solution followed by thorough saline irrigation and then final irrigation with chlorhexidine. An interappointment intracanal dressing of calcium hydroxide was given for two weeks which was changed at every week, after which obturation was completed using cold lateral compaction technique with appropriate gutta-percha points and AH Plus sealer (Figure 2). Post endodontic filling was done with composite (Figure 3).

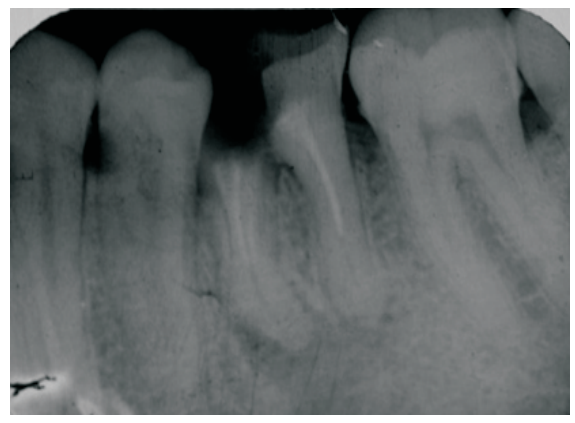

Fig-1: Pre-Operative IOPAR showing gross decay, incompletely obturated canals and periapical radiolucency

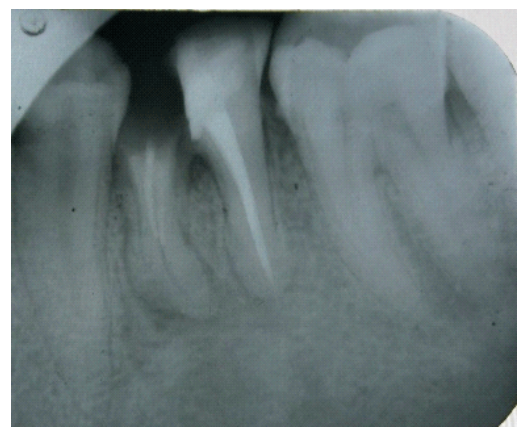

Fig- 2: Re-RCT and Obturation of distal root, to be retained after Hemisection

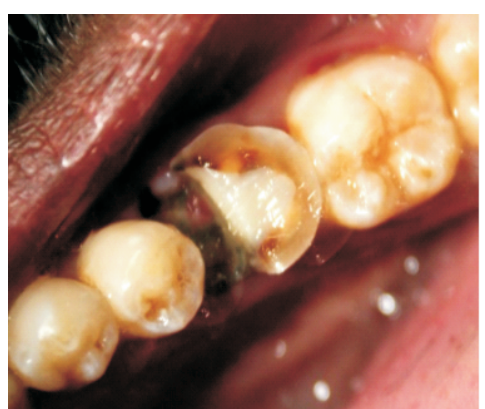

Fig-3: Clinical picture after Endodontic therapy

Patient was recalled the next day for the hemisection procedure. The mesial and distal roots were sectioned at the level of the furcation using long tapered fissure diamond point and a radiograph was taken to confirm the complete separation. After completion of the sectioning, the mesial root was luxated and along with the coronal part it was removed from the socket with an extraction forcep (Figure $4 \& 5$ ). The socket was irrigated adequately with normal saline to remove bony chips. A finishing diamond bur was used to smoothen the mesial surface of the distal root and its coronal portion. The extraction socket was sutured with 4-0 mersilk suture material and covered with a periodontal dressing (Coe pack) (Figure-6).

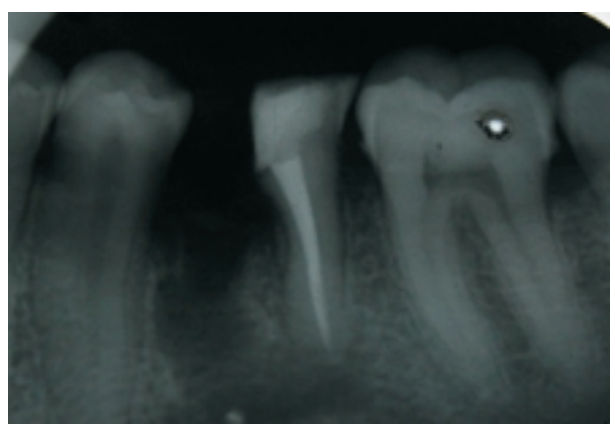

Fig-4: IOPAR of Extraction of Mesial half of tooth

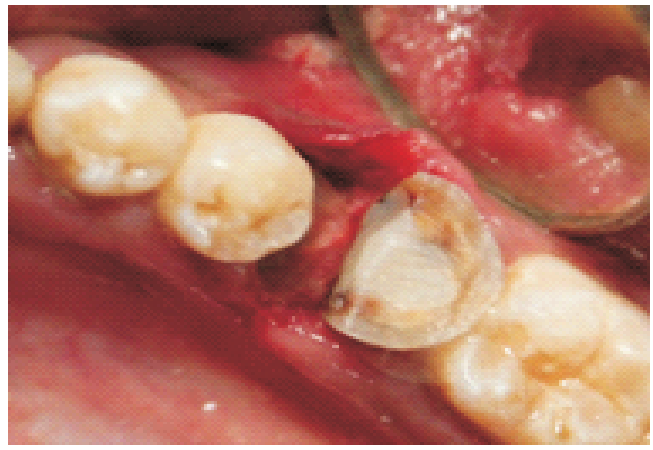

Fig-5: Clinical picture after extracting mesial half of tooth 


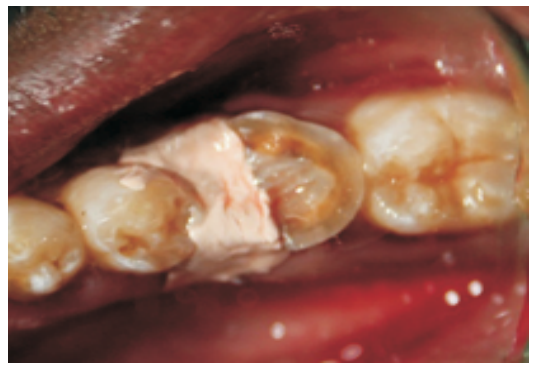

Fig-6: Suturing of surgical site with 4-0 mersilk suture material and covered with Coe-pack periodontal dressing

Patient was recalled after one week for evaluation. At this visit clinical examination revealed healed extracted site, thus irrigation with betadiene was done and sutures were removed (Figure-7).

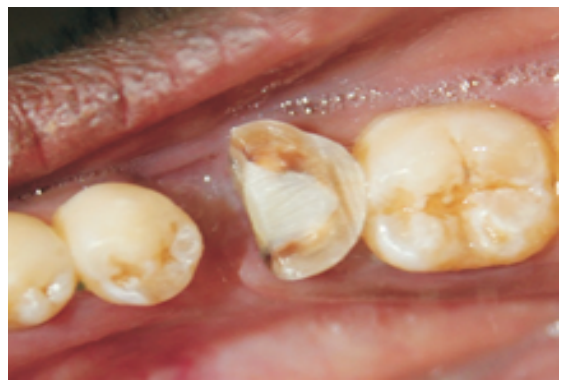

Fig-7: At week Suture removal

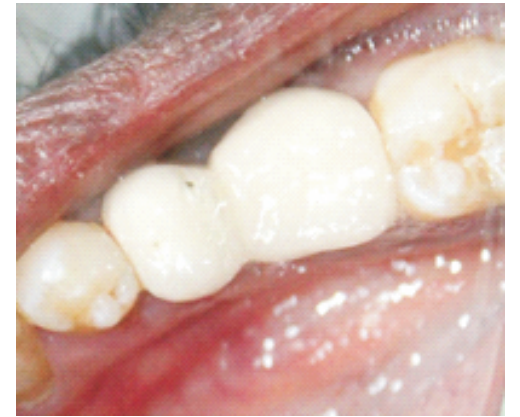

Fig-8: Porcelain fused to metal joint crown placed on hemisectioned molar (36) and premolar (35) asabutment

Crown preparation for Porcelain fused to metal crowns was done using distal segment of mandibular first molar and second premolar as abutments. Impression was made and die was fabricated. After 1 week final prosthesis was placed (Figure-8).

At 1-month recall visit, healing was found to be satisfactory, Radiographs at 3 months and 9 months suggested progressive formation of bone in the extraction socket along with resolution of radiolucency around the distal root of tooth no. [36].
Figure 9 shows follow up radiograph at 1 year which shows complete resolution of periapical radiolucency and bone formation.

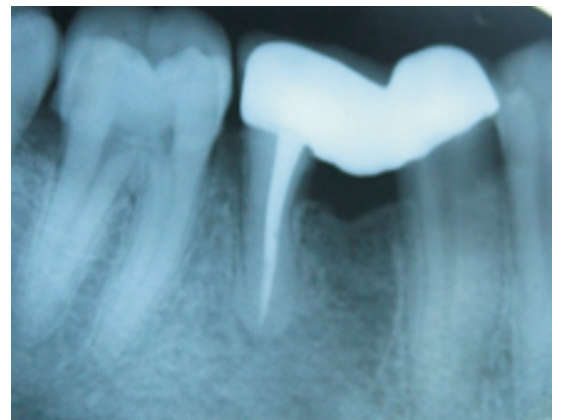

Fig-9: IOPAR of 1year follow-up

\section{Discussion:}

Hemisection also known as root amputation is a useful alternative procedure to save those multi-rooted teeth which have been indicated for extraction. It is a relatively simple, conservative, inexpensive treatment with good chances of success provided appropriate case selection has been done. 4

Weine 5 has given an insight on the specific indications where this procedure should be considered.

1. Severe vertical bone loss involving only one root of multi-rooted teeth.

2. Through and through furcation destruction.

3. Unfavourable proximity of roots of adjacent teeth, preventing adequate hygiene maintenance in proximal areas.

4. Severe root exposure due to dehiscence.

5. Prosthetic failure of abutments within a splint.

6. Perforation through the floor of the pulp chamber.

7. Vertical fracture of one root.

Apart from considering these factors patient's oral hygiene status, caries index and medical status should also be considered for hemisection procedure. Park et al. has also suggested that hemisection is a reliable treatment option for molars with questionable prognosis as it will maintain the teeth without detectable bone loss for a long-term period, provided that the patient has optimal oral hygiene.6 Also, accessibility of root furcation for easy separation as well as good bone support for the remaining root should be assessed.7

In the present case there was complete furcation involvement and the distal half of the tooth was sound. Thus considering 
these factors and patients financial constraint hemisection was chosen as the treatment of choice. This case demonstrates hemisection as an alternative treatment to extraction of a whole tooth and salvation of healthy tooth structure.

This treatment offers a predictable treatment option with a prognosis comparable to any tooth with an endodontic treatment. 8 The overall survival rates of a large number of root-resected molars by Yuhet al. in a retrospective study was found to be $91.1 \% .9$ In another study by Carnevale et al. a survival rate of about $93 \%$ over a 10 -year follow-up have been reported in cases where hemisection was done for the management of furcated molars. 10

In the present case, good prognosis was observed as evident by healing of periapical lesion, proper occlusion, absence of mobility and healthy periodontal condition up to 1 year of follow-up.

Thus following a firm set of criteria for case selection and specific endodontic, surgical, and restorative guidelines hemisection can prove to be a reliable treatment option in saving molar teeth once considered non restorable. It has also been suggested that hemisection should be considered before every molar extraction, as it offers successful longterm results.11-13

\section{Conclusion:}

Hemisection can be considered as a predictable treatment option for a hopeless tooth and with advancements in endodontics, periodontics and restorative dentistry, it has received further acceptance. The key is the meticulous case selection and the treatment goal is to try and maintain what is present for restoration of the function.

\section{References:}

1. Arora A, Arya A, Singhal RK, Khatana R. Hemisection: A conservative approach. Indian J Dent Sci 2017;9:206-9.

2. Sharma S, Sharma R, Ahad A, Gupta ND, Mishra SK. Hemisection as a Conservative Management Of Grossly Carious Permanent Mandibular First Molar. J Nat Sci Biol Med 2018;9(1):97-99.

3. Green, E. N. (1986). Hemisection and root amputation. The Journal of the American Dental Association, 112(4), 511-518.

4. Mittal P, Prasad AB, RaisinganiD,Amit, Mehta P, Soni D, Khurana D. Hemisection: A Savior for Hopeless Teeth. J Mahatma Gandhi Univ Med Sci Tech 2016;(1):30-34.
5. Weine FS. Endodontic Therapy. 5th ed. St. Louis, USA: Mosby; 1996. p. 154-68.

6. Park JB. Hemisection of teeth with questionable prognosis. J Int AcadPeriodontol 2009;11(3),214-19.

7. Haskell EW, Stanley HR. Vital hemisection of mandibular second molar. J Am Dent Assoc 1981;102:503-6.

8. Babaji P, Sihag T, Chaurasia VR, Senthinathan S. Hemisection: A conservative management of periodontally involved molar tooth in a young patient. $\mathrm{J}$ Nat Sci Biol Med 2015;6(1):253-5.

9. Yuh DY, Lin FG, Fang WH, Chien WC, Chung CH, Mau LP, et al. The impact of medical institutions on the treatment decisions and outcome of root-resected molars: A retrospective claims analysis from a representative database. J Med Sci. 2014;34:1-8.

10. Carnevale G, Di Febo G, Tonelli MP, Marin C, Fuzzi M. A retrospective analysis of the periodontal-prosthetic treatment of molars with interradicular lesions. Int $\mathrm{J}$ Periodontics Restorative Dent. 1991;11:189-205.

11. Sharma S, Tiwari RK, Mishra SK, Kharade PP. Conservative management of grossly carious mandibular first molar with a hemisection approach. Gen Dent 2015;63(4):19-21.

12. Saaad MN, Moreno J, Crawford C. Hemisection as an aiternative treatment for multirooted terminal abutment: A case report. J Can Dent Assoc 2009;75(5),387-90.

13. Schmitt SM, Brown FH. The Hemisected Mandibular Molar: A Strategic Abutment. J Prosthet Dent $1987 ; 58(2), 140-45$. 